\title{
Development and Evaluation of a Pulse Driven-type Electromagnetic Control Expansion Valve applied to a Small Scale Refrigerant Cycle (Part I: Theoretical estimation of pressure drop)
}

\author{
Yujiro Kitaide ${ }^{1}$, Naoki Maruyama ${ }^{1}$, Masafumi Hirota ${ }^{1}$, \\ Yusuke Onishi ${ }^{2}$, Toshiaki Tsuchiya ${ }^{2}$ \\ ${ }^{1}$ (Graduate School of Engineering, Mie University, Tsu, Mie, Japan) \\ ${ }^{2}$ (Fuji Electric Co., Ltd., Yokkaichi, Mie, Japan)
}

\begin{abstract}
The application of a new pulse driven-type electromagnetic control expansion valve to an R744 cycle is proposed and the characteristics of the valve are theoretically evaluated and experimentally inspected in this paper. In this theoretical estimation, the structure of the valve is simulated using elements such as ducts, a pin hole, a groove and an orifice. The pressure drops caused by each element that make up the valve are estimated individually. The V-shaped groove and its entrance and exit interfaces create the majority of the overall resultant pressure drop. Especially, the influence of the machining tolerance is also estimated because the elements that make up the valve are very fine. Then, the validity of this estimation is verified by an experiment. The experiment is conducted by constructing a refrigerator cycle. The theoretically estimated pressure drop agrees with the experimental results even through the two-phase refrigerant fluid flow field. As a result, it was shown that the electromagnetic control expansion valve proposed in this paper can control the pressure drop in a way suitable for satisfying cooling demand. Also, the theoretical estimation proposed in this paper may be able to be applied for the estimation of the pressure drop of the expansion valve.
\end{abstract}

Keywords: Electric expansion valve, Electromagnetic control, Refrigerator, Pulse drive, $\mathrm{CO}_{2}(\mathrm{R} 744)$

\section{Introduction}

A small scale refrigerant unit has been applied in many very popular cooling systems such as refrigerators and air conditioners. Generally, the electric consumption of the system for home use is less than 1 $\mathrm{kW}$. However, a large number of produced units have been being used in the world. Especially, refrigerators and air conditioners in developing countries have become popular alongside those being used in advanced countries in recent years. The total energy consumption of this sector will likely increase in the future. Therefore, the research and development of energy-conserving technologies is important in this sector. Here, the energy consumption of the system primarily occupies the interest of system performance.

Generally, low temperature heat, such as that applied to an air conditioning unit or a fridge, is obtained from a heat pump or refrigerator using a refrigerant cycle. The cycle contains a refrigerant as a working fluid; a majority of currently used refrigerants are harmful to the environment, including causing problems such as the greenhouse effect. Accordingly, a heat pump using $\mathrm{CO}_{2}(\mathrm{R} 744)$ as a working fluid has been introduced in recent years. $\mathrm{CO}_{2}$ is a natural refrigerant which has a lower greenhouse effect when compared to conventional artificial refrigerants. Heat pumps using R744 can be assumed to create a more environmentally-friendly refrigerator. However, the electric consumption of the heat pump that uses R744 becomes higher than that of a conventional refrigerant cycle with an artificial refrigerant, because the refrigerant needs high compression pressure in the cycle. Therefore, the development of an energy-conserving heat pump with R744 has been expected. The optimum control of the elements that make up the system, such as an electric expansion valve, suitable for the operation condition has been investigated [1].

The refrigerant cycle consists of a compressor, a condenser, a decompression device and an evaporator. A capillary tube or an expansion valve is generally employed as a decompression device. The electronic control expansion valve is examined in this paper. The electronic control expansion valve can control the pressure drop of a refrigerant continuously from the liquid to the two-phase state appropriate to the cooling demand. It contributes to the energy-conserving operation of the refrigerator. The R744 cycle has a higher decompression and lower volume flow rate than other conventional refrigerant cycles at equal system capacity. The decompression of the refrigerant is caused by the use of the expansion valve with a microchanel and an orifice. The flow patterns of R744 passing through a microchanel or a short orifice are very complicated, because the fluid starts boiling and expands when it passes through these elements. The flow characteristics, especially for a pressure drop in a microchanel, have been examined [2-6]. On the other hand, the flow 
characteristics of R744 are evaluated and compared with the results obtained from R-134a [7, 8]. The flow rates of the refrigerants passing through a narrow tube are examined, excluding the flow rate for R744 [9-11]. The influence of the valve opening degree of the expansion valve on system performance is also important as a piece of equipment $[10,12]$.

A pulse driven-type electromagnetic control expansion valve is one of the most promising pieces of decompression equipment for refrigerant cycles. In this paper, the application of a new pulse driven-type electromagnetic control expansion valve to R744 cycle is proposed, and the characteristics of the valve are theoretically evaluated and experimentally inspected.

\section{Theoretical Analysis of Decompression in Pulse Driven-type Electromagnetic Control Expansion Valve}

The pressure drop of the refrigerant is caused by the loss of fluid while passing through the narrow duct. The losses are classified as rapid-contraction, rapid-expansion and friction losses, as shown in Fig. 1.

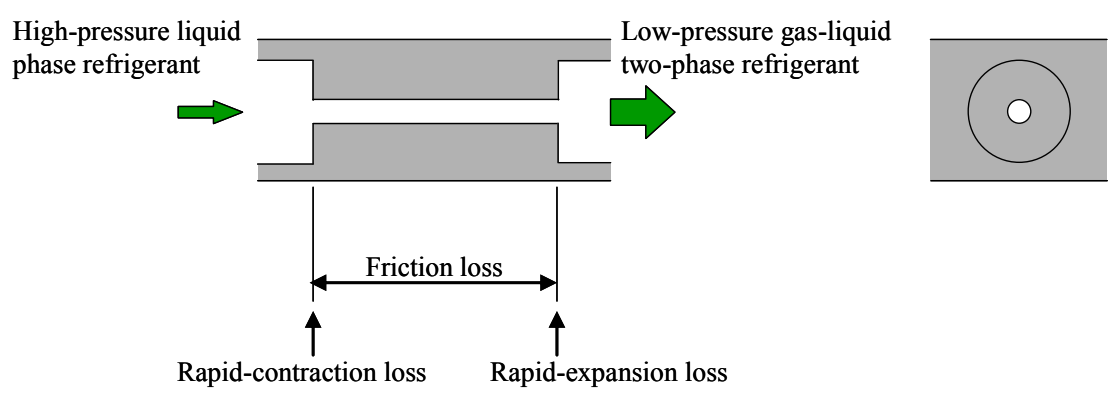

Figure 1 Losses of fluid passing through the narrow duct

Liquid refrigerant enters the narrow duct from the high pressure tube. The diameter of the narrow duct is less than $1 \mathrm{~mm}$, in general. Here, the refrigerant sustains a rapid-contraction loss. Then, the refrigerant decompresses at the narrow duct by friction loss between the duct's surface and the fluid. The refrigerant sustains a rapid-expansion loss when it flows out from the narrow duct.

The overall decompression caused at the expansion valve is estimated by combining these elements. If the liquid refrigerant downwardly crosses the saturation liquid line of the Mollier chart, namely the pressure of the refrigerant becomes lower than the saturation liquid line at a certain temperature, the liquid refrigerant will come to a boil. The refrigerant enters into a gas-liquid two-phase state. The fluid state of a refrigerant is very complicated in the decompression area because the state changes from a liquid to a two-phase. It is one of the special characteristics of refrigerant flow that a single phase fluid flow does not have. Here, the three losses mentioned above are estimated by following the equations as a first step.

$$
\begin{aligned}
& \text { Rapid-contraction loss: } \Delta p_{c}=\xi \frac{V_{s}^{2}}{2} \rho \\
& \text { Friction loss of duct: } \Delta p_{f}=\lambda \frac{l}{d} \frac{V^{2}}{2} \rho \\
& \text { Rapid-expansion loss: } \Delta p_{e}=\zeta\left(1-\frac{A_{s}}{A_{l}}\right)^{2} \frac{V_{s}^{2}}{2} \rho
\end{aligned}
$$

Total pressure drop of this element is estimated by Eq. (4).

$$
\Delta p_{t}=\Delta p_{c}+\Delta p_{f}+\Delta p_{e}
$$

The friction coefficient of the duct is estimated by well known Eqs. (5) and (6) proposed by Blasius or Nikuradse, respectively. These coefficients are functions of Reynolds number. These equations can be applied to single phase fluid flow. However, these are applied to the two-phase fluid flow by estimating Reynolds number for the two-phase fluid flow at a certain quality as a first step estimation.

$$
\begin{aligned}
& \lambda=0.3164 \operatorname{Re}^{-0.25}\left(\operatorname{Re}=3 \times 10^{3}-1 \times 10^{5}\right) \\
& \lambda=0.0032+0.221 R e^{-0.237}\left(\operatorname{Re}=1 \times 10^{5}-3 \times 10^{6}\right)
\end{aligned}
$$

The loss coefficient of rapid contraction in Eq. (1) is also important. It depends on the shape of the interface between the larger and smaller ducts. The coefficient is expressed by empirical equation, Eq. (7), in 
this paper.

$$
\xi=0.481-0.489\left(A_{s} / A_{l}\right)
$$

On the other hand, the loss coefficient of rapid expansion will be estimated using only the function of the ratio of cross sections of the ducts. Therefore, $\zeta$ is assumed as 1.0 in general.

The principal configuration of the pulse driven-type electromagnetic control expansion valve employed in this paper is shown in Fig. 2. The overall pressure drop caused by the valve will be theoretically estimated, and then the applicability of the valve to the actual system will be examined. The valve consists of a pin hole, a groove, an orifice and a plunger. The plunger is moved up and down by an electromagnet. High pressure liquid refrigerant which comes from a condenser flows into a cylinder at first. Then, it passes through a pin hole, and is separated into two V-shaped grooves. The cross section of the grooves with a crescent-shaped area will be controlled by the vertical motion of the plunger. The flow rate of the refrigerant increases as the cross section of the groove becomes larger when the plunger moves downward. At the same time, the inlet area of the orifice becomes gradually narrower as the position of the plunger gets lower. Finally, the flow of refrigerant will be stopped when the plunger has moved to the lowest point and it comes into contact with the orifice. The flow rate of refrigerant is controlled by the position of the plunger and its period of motion. A pulse driven-type electromagnetic control expansion valve has a simple structure compared to a conventional electric expansion valve which is controlled by a stepping motor. The motion of the plunger is faster than the conventional valve, too. During the movement of the plunger, refrigerant passes through an orifice, and flows out from the valve toward the evaporator.
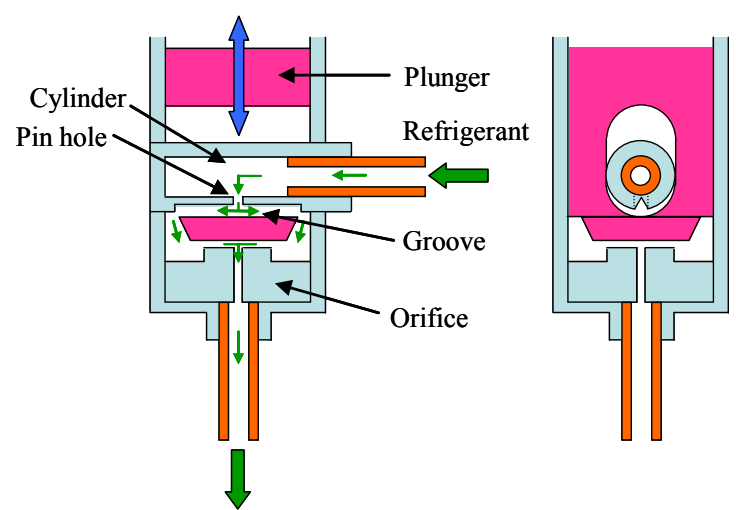

Figure 2 Principal configuration of pulse driven-type electromagnetic control expansion valve

Figure 3 shows a flow model of the valve for theoretical estimation which corresponds to Fig. 2. The pressure drop of refrigerant is caused by the loss of fluid flow through the elements. The structure of the Vshaped groove is shown in Fig. 3(b). The hydraulic diameter of the groove is estimated by a concept of an equivalent hydraulic diameter. The overall pressure drop will be estimated by integrating the pressure drops estimated from each element.

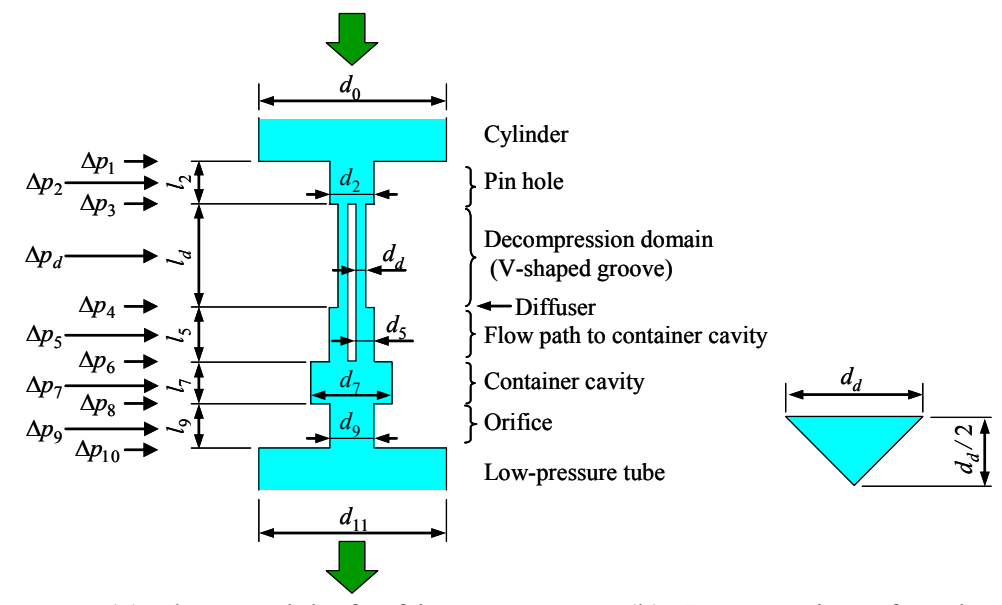

(a) Flow model of refrigerant

(b) Cross section of V-shaped groove

Figure 3 Flow model of pulse driven-type electromagnetic control expansion valve 


\subsection{Calculation conditions for the pressure drop}

\section{Results and Discussion}

The specifications of the valve and the index of the parameter are shown in Table 1. These sizes are introduced and refer to the conventional expansion valve. R744 is employed as a working fluid. Figure 4 shows a part of the Mollier chart of R744. The red striped area shows the inlet pressure and temperature of R744 to the valve. The blue area shows the outlet condition of R744. These conditions are estimated based on the empirical conditions for a small scale R744 refrigerator. The temperature difference of R744 between inlet and outlet is around $10{ }^{\circ} \mathrm{C}$, and the quality of $\mathrm{R} 744, x$, is between $0<x<0.2$. Table 2 shows the conditions for the theoretical estimation. The processing accuracy of the V-shaped groove is introduced in this estimation. The accuracy of processing for a groove may affect the pressure drop of each section because the size of the groove is very small. The accuracy is set here to $\pm 0.01 \mathrm{~mm}$ for $d_{d}$. The pressure drop of the valve will be estimated under these conditions.

Table 1 Specification of the valve for theoretical estimation

\begin{tabular}{|c|c|c|c|c|c|}
\hline Index & Elements & Hydraulic diameter $d(\mathrm{~mm})$ & Length $l(\mathrm{~mm})$ & Loss coefficient & Phase state \\
\hline 0 & Cylinder & 3.0 & & & \multirow{4}{*}{ Liquid } \\
\hline 1 & Rapid-contraction & & & $\xi=f\left(A_{s} / A_{l}\right)$ & \\
\hline 2 & Pin hole & 0.6 & 0.88 & $\lambda=f(\operatorname{Re})$ & \\
\hline 3 & Rapid-contraction & & & $\xi=f\left(A_{s} / A_{l}\right)$ & \\
\hline$d$ & Decompression domain & $\left(d_{d}\right) 0.3-0.45$ & $3.8 \times 2$ & $\lambda=f(R e)$ & Transition \\
\hline 4 & Rapid-expansion & & & $\zeta=1.0, A_{s}=f\left(d_{d}\right)$ & \multirow{8}{*}{$\begin{array}{l}\text { Gas-liquid } \\
\text { two-phase }\end{array}$} \\
\hline 5 & Flow path to container cavity & 1.1 & $2.8 \times 2$ & $\lambda=f(R e)$ & \\
\hline 6 & Rapid-contraction & & & $\zeta=1.0$ & \\
\hline 7 & Container cavity & 1.85 & $4.1 \times 2$ & $\lambda=f(R e)$ & \\
\hline 8 & Rapid-contraction & & & $\xi=f\left(A_{s} / A_{l}\right)$ & \\
\hline 9 & Orifice & 0.6 & 4.0 & $\lambda=f(\operatorname{Re})$ & \\
\hline 10 & Rapid-expansion & & & $\zeta=1.0$ & \\
\hline 11 & Low pressure tube & 2.76 & & & \\
\hline
\end{tabular}

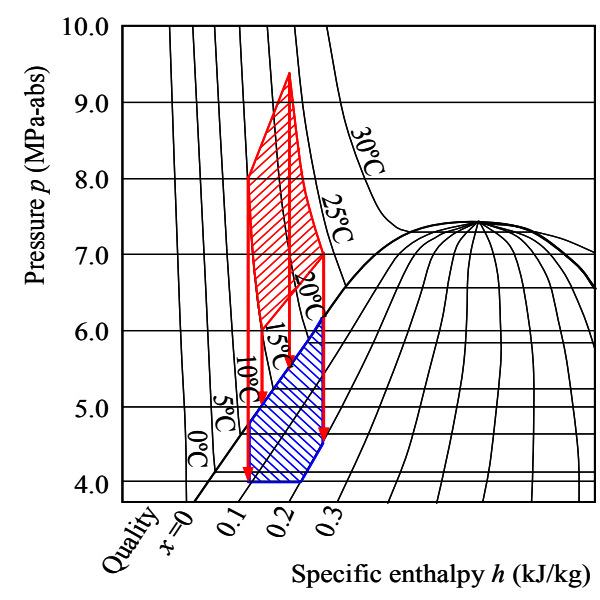

Figure 4 A part of R744 Mollier chart

Table 2 Calculation condition for refrigerant and V-shaped groove

\begin{tabular}{|l|l|}
\hline Refrigerant & $\mathrm{R} 744\left(\mathrm{CO}_{2}\right)$ \\
\hline Inlet pressure: $p_{1}$ & $6-9 \mathrm{MPa}$ \\
\hline Inlet temperature: $T_{\text {in }}$ & $15,23^{\circ} \mathrm{C}$ \\
\hline Outlet pressure: $p_{10}$ & $4-6 \mathrm{MPa}$ \\
\hline Outlet temperature: $T_{\text {out }}$ & $13^{\circ} \mathrm{C}$ for $T_{\text {in }}=23^{\circ} \mathrm{C}, 5^{\circ} \mathrm{C}$ for $T_{i n}=15^{\circ} \mathrm{C}$ \\
\hline Mass flow rate: $\dot{m}$ & $2.0-7.0(\mathrm{~g} / \mathrm{s}), 1.0 \mathrm{~g} / \mathrm{s} \mathrm{steps}$ \\
\hline Quality: $x$ & $0-0.2$ \\
\hline V-shaped groove width: $d_{d}$ & $0.3-0.45 \mathrm{~mm}, 0.05 \mathrm{~mm}$ steps \\
\hline Processing accuracy of V-shaped groove & $\pm 0.01 \mathrm{~mm}$ for $d_{d}$ \\
\hline
\end{tabular}




\subsection{Theoretically estimated pressure drop of the valve}

Figure 5 shows a component ratio of the pressure drop of each element. The quality of refrigerant at the exit of the V-shaped groove and after is varied from 0 to 0.2 , and the properties of the two-phase refrigerant are estimated by the $\mathrm{CO}_{2}$ table and the Mollier chart. The overall pressure drop increases as the mass flow rate increases, because the flow velocity increases. The pressure drop increases as the fluid temperature upon exit increases, because Reynolds number becomes smaller and the friction coefficient becomes larger. On the other hand, the overall pressure drop decreases as the quality of the gas at the exit increases, even though the volume flow rate increases. It depends on the relationship of Reynolds number and velocity of the refrigerant.

There is a significant impact of groove size on the pressure drop in each mass flow rate, especially for higher mass flow rates. The higher pressure drops, $\Delta p_{3}, \Delta p_{d}$ and $\Delta p_{4}$, are caused at the rapid contraction, friction loss at V-shaped groove and rapid expansion areas, respectively. Almost the entire pressure drop is caused by these portions. On the other hand, the pressure drops at the pin hole, orifice and ducts are quite small. Therefore, it is very important to produce the V-shaped groove preciously.

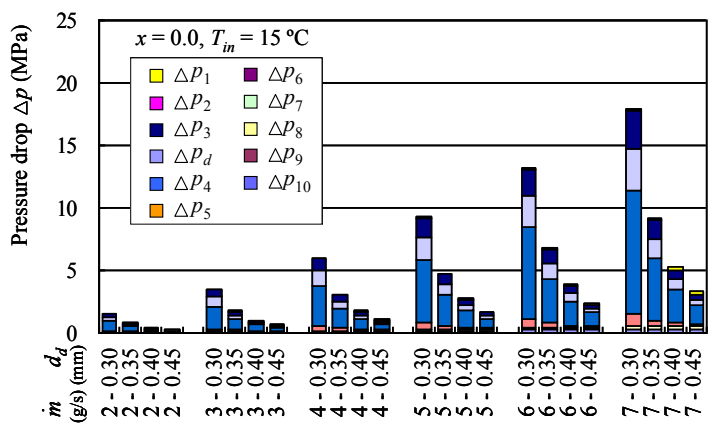

(a) $x=0, T_{\text {in }}=15^{\circ} \mathrm{C}$

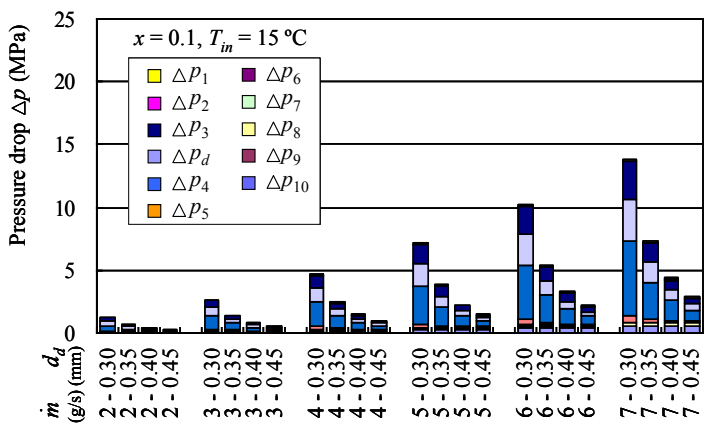

(c) $x=0.1, T_{\text {in }}=15^{\circ} \mathrm{C}$

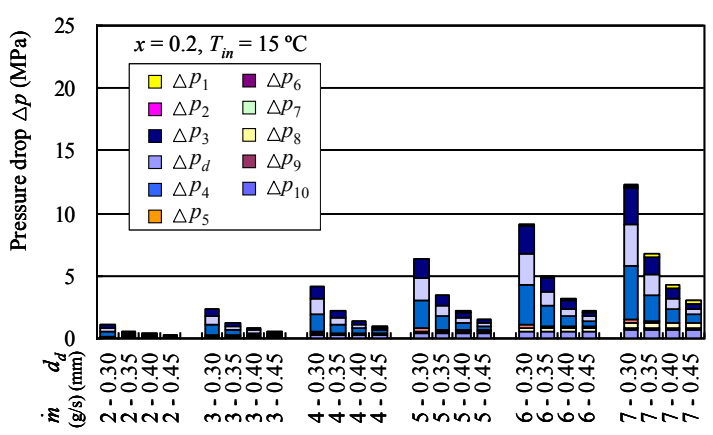

(e) $x=0.2, T_{i n}=15^{\circ} \mathrm{C}$

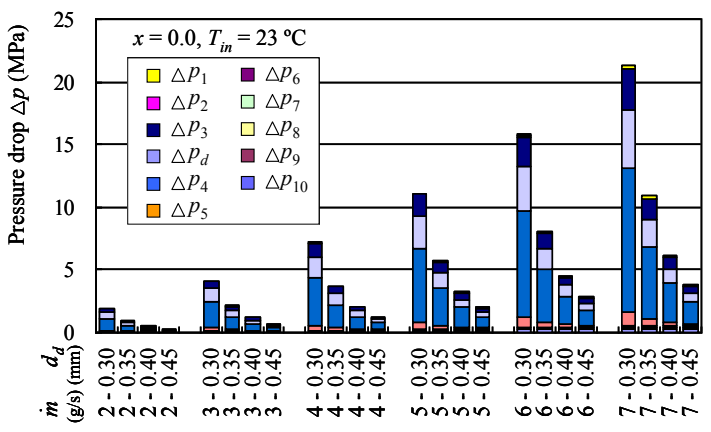

(b) $x=0, T_{\text {in }}=23^{\circ} \mathrm{C}$

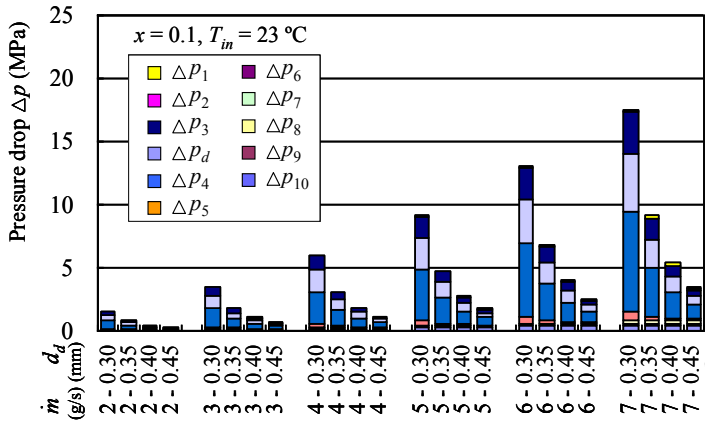

(d) $x=0.1, T_{\text {in }}=23^{\circ} \mathrm{C}$

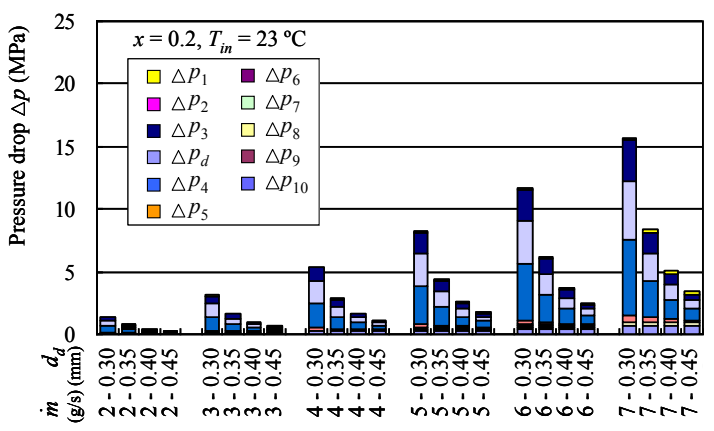

(f) $x=0.2, T_{\text {in }}=23{ }^{\circ} \mathrm{C}$

Figure 5 Example of pressure drop in each element

Figure 6 shows the theoretically estimated overall pressure drop caused by the expansion valve. The marks show the estimated pressure drop obtained from each prescribed groove width. The solid lines and chain lines are the error range for a groove width estimated by $\pm 0.01 \mathrm{~mm}$ machining tolerance. The pressure drop required for the valve is around 0 to $5 \mathrm{MPa}$. The pressure drop estimated for $d_{d}=0.30 \mathrm{~mm}$ is very sensitive concerning the mass flow rate. It means it is difficult to control the pressure drop carefully. 
An example of the experimental result for $d_{d}=0.40 \mathrm{~mm}$ is also shown in Fig. 6. Figure 7 shows the system layout of the experimental apparatus. The experimental system consists of a compressor, a condenser, a test section as expansion valve and an evaporator. The detail of the test section is omitted in this paper. The test section is manufactured to simulate the expansion valve shown in Figs. 2, 3 and Table 1. The experiment is conducted based on the conditions shown in Table 2. However, $d_{d}$ is fixed at $0.40 \mathrm{~mm}$. The plunger is set at the upper position in Fig. 2, which means the refrigerant flows in the V-shaped groove only without a crescentshaped area. The theoretically estimated results agree well with the experimental results for $d_{d}=0.40 \mathrm{~mm}$ even through the very complicated two-phase flow field. The pressure drops for $x=0$ are estimated for reference. The quality should be chosen as $x=0.1$ to 0.2 in this estimation. The theoretical estimation mentioned above may be able to be applied for the estimation of the pressure drop of the expansion valve.

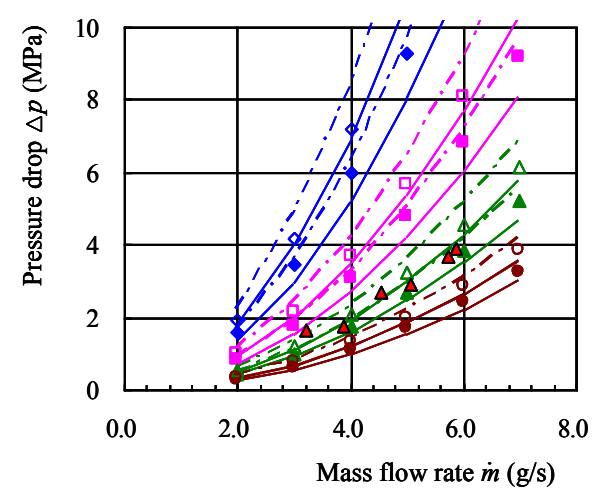

(a) $x=0$

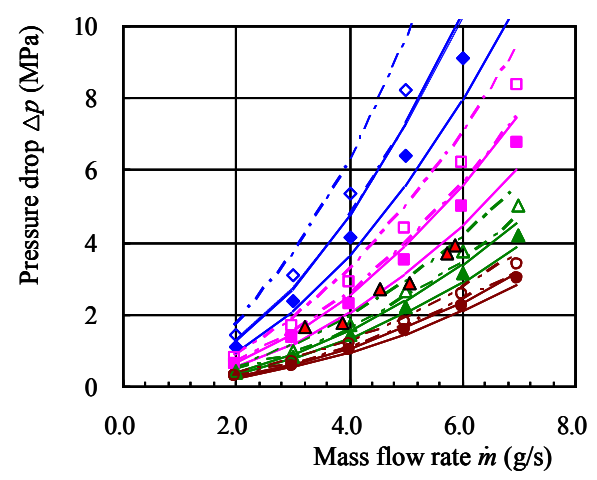

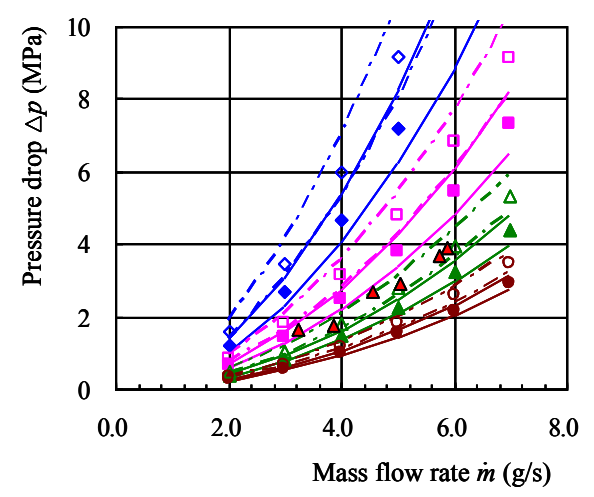

(b) $x=0.1$

\begin{tabular}{|c|c|c|c|}
\hline$T_{\text {in }}\left({ }^{\circ} \mathrm{C}\right)$ & $T_{\text {out }}\left({ }^{\circ} \mathrm{C}\right)$ & $d_{d}(\mathrm{~mm})$ & $d_{d^{+}}+, d_{d^{-}}$ \\
\hline \multirow{4}{*}{15} & \multirow{4}{*}{5} & $0.30>$ & - \\
\hline & & 0.35 & - \\
\hline & & $0.40 \triangle$ & - \\
\hline & & $0.45 \bigcirc$ & - \\
\hline \multirow{4}{*}{23} & \multirow{4}{*}{13} & $0.30 \diamond$ & $-\cdot-$ \\
\hline & & $0.35 \square$ & $-\cdot-$ \\
\hline & & $0.40 \triangle$ & $-\cdot-$ \\
\hline & & $0.45 \bigcirc$ &.-- \\
\hline \multicolumn{2}{|c|}{ Experiment } & $0.40 \triangle$ & \\
\hline
\end{tabular}

(c) $x=0.2$

Figure 6 Theoretically estimated pressure drop and example of experimental result

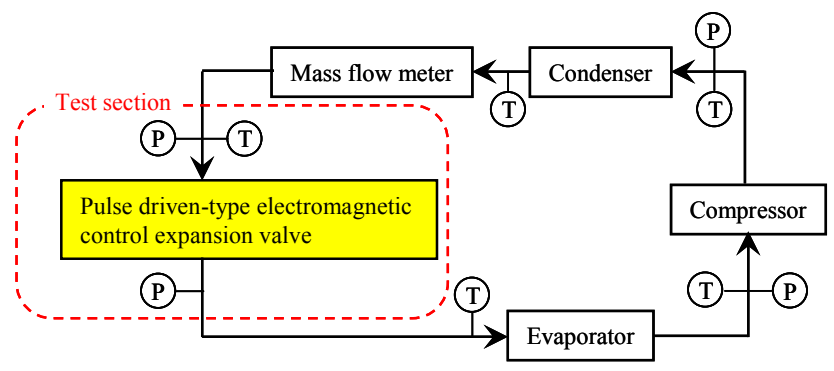

Figure 7 System layout of experimental apparatus

\section{Conclusions}

The application of a new pulse driven-type electromagnetic control expansion valve to an R744 cycle is proposed, and the characteristics of the valve are theoretically evaluated and experimentally inspected in this paper. In the theoretical estimation, the pressure drop caused by each element that makes up the valve is estimated. The V-shaped groove, its entrance and exit interfaces occupy the majority of the overall pressure drop. Especially, the influence of the machining tolerance is also estimated. Then the validity of this estimation 
is inspected by experiment. The theoretically estimated pressure drop well agrees with the experimental results even through the two-phase refrigerant fluid flow field. As a result, the theoretical estimation mentioned above may be able to be applied to the estimation of the pressure drop of the expansion valve. It was shown that the electromagnetic control expansion valve proposed in this paper can control the pressure drop suitable for the cooling demand.

$\begin{array}{lll}A: & \text { Cross section of duct }\left[\mathrm{m}^{2}\right] & \text { Nomenclature } \\ d: & \text { Hydraulic diameter of duct }[\mathrm{m}] \\ h: & \text { Specific enthalpy }[\mathrm{J} / \mathrm{kg}] \\ l: & \text { Length }[\mathrm{m}] \\ \dot{m}: & \text { Mass flow rate }[\mathrm{kg} / \mathrm{s}] \\ p: & \text { Pressure }[\mathrm{Pa}] \\ R e: & \text { Reynolds number }(=\rho V d / \mu)[-] \\ T: & \text { Temperature }\left[{ }^{\circ} \mathrm{C}\right] \\ V: & \text { Velocity }[\mathrm{m} / \mathrm{s}] \\ x: & \text { Quality }[-] \\ \zeta: & \text { Loss coefficient }(\approx 1)[-] \\ \lambda: & \text { Friction coefficient of pipe }[-] \\ \mu: & \text { Viscosity }[\mathrm{Pa} \cdot \mathrm{s}] \\ \xi: & \text { Loss coefficient }[-] \\ \rho: & \text { Density }\left[\mathrm{kg} / \mathrm{m}^{3}\right]\end{array}$

\section{Subscripts}

$\begin{array}{ll}0-11: & \text { index of element } \\ c: & \text { contraction } \\ d: & \text { V-shaped groove } \\ e: & \text { expansion } \\ f: & \text { friction } \\ \text { in: } & \text { inlet } \\ l: & \text { larger side } \\ \text { out: } & \text { outlet } \\ s: & \text { smaller side } \\ t: & \text { total }\end{array}$

\section{References}

[1] C. Baek, J. Heo, J. Jung, H. Cho and Y. Kim, Optimal control of the gas-cooler pressure of a CO ${ }_{2}$ heat pump using EEV opening and outdoor fan speed in the cooling mode, International Journal of Refrigeration, 36(4), 2013, 1276-1284.

[2] A. S. Pamitran, K. I. Choi, J. T. Oh and H. K. Oh, Two-phase pressure drop during $\mathrm{CO}_{2}$ vaporization in horizontal smooth minichannels, International Journal of Refrigeration, 31(8), 2008, 1375-1383.

[3] R. Revellin and J. R. Thome, Adiabatic two-phase frictional pressure drops in microchannels, Experimental Thermal and Fluid Science, 31, 2007, 673-685.

[4] J. Pettersen, Flow vaporization of $\mathrm{CO}_{2}$ in microchannel tubes, Experimental Thermal and Fluid Science, 28(2-3), 2004, 111-121.

[5] A. Cavallini, D. Del Col and L. Rossetto, Heat transfer and pressure drop of natural refrigerants in minichannels, International Journal of Refrigeration, 36(2), 2013, 287-300.

[6] M. Ducoulombier, S. Colasson, J. Bonjour and P. Haberschill, Carbon dioxide flow boiling in a single microchannel - Part I: Pressure drops, Experimental Thermal and Fluid Science, 35(4), 2011, 581-596.

[7] T. N. Tran, M. C. Chyu, M. W. Wambsganss and D. M. France, Two-phase pressure drop of refrigerants during flow boiling in small channels: an experimental investigation and correlation development, International Journal of Multipase Flow, 26(11), 2000, 17391754.

[8] J. P. Liu, Y. M. Niu, J. P. Chen, Z. J. Chen and X. Feng, Experimentation and correlation of R744 two-phase flow through short tubes, Experimental Thermal and Fluid Science, 28(6), 2004, 565-573.

[9] W. Li, Simplified modeling analysis of mass flow characteristics in electronic expansion valve, Applied Thermal Engineering, 53(1), 2013, 8-12.

[10] L. Chen, J. Liu, J. Chen and Z. Chen, A new model of mass flow characteristics in electronic expansion valves considering metastability, International Journal of Thermal Science, 48(6), 2009, 1235-1242.

[11] C. Park, H. Cho, Y. Lee and Y. Kim, Mass flow characteristics and empirical modeling of R22 and R410A flowing through electronic expansion valves, International Journal of Refrigeration, 30(8), 2007, 1401-1407.

[12] Y. Hou, J. Ma, C. Liu, J. Cao and X. Liu, Experimental investigation on the influence of EEV opening on the performance of transcritical $\mathrm{CO}_{2}$ refrigeration system, Applied Thermal Engineering, 65(1-2), 2014, 51-56. 